Article

\title{
Silencing and Oblivion of Psychological Trauma, Its Unconscious Aspects, and Their Impact on the Inflation of Vajrayāna. An Analysis of Cross-Group Dynamics and Recent Developments in Buddhist Groups Based on Qualitative Data
}

\author{
Anne Iris Miriam Anders \\ Institute of Social and Cultural Anthropology, Ludwig-Maximilians-University Munich, 80939 Munich, \\ Germany; Miriam.Anders@campus.lmu.de
}

Received: 8 October 2019; Accepted: 6 November 2019; Published: 10 November 2019

\begin{abstract}
The commercialization of Buddhist philosophy has led to decontextualization and indoctrinating issues across groups, as well as abuse and trauma in that context. Methodologically, from an interdisciplinary approach, based on the current situation in international Buddhist groups and citations of victims from the ongoing research, the psychological mechanisms of rationalizing and silencing trauma were analyzed. The results show how supposedly Buddhist terminology and concepts are used to rationalize and justify economic, psychological and physical abuse. This is discussed against the background of psychological mechanisms of silencing trauma and the impact of ignoring the unconscious in that particular context. Inadequate consideration regarding the teacher-student relationship, combined with an unreflective use of Tibetan honorary titles and distorted conceptualizations of methods, such as the constant merging prescribed in so-called 'guru yoga', resulted in giving up self-responsibility and enhanced dependency. These new concepts, commercialized as 'karma purification' and 'pure view', have served to rationalize and conceal abuse, as well as to isolate the victims. Therefore, we are facing societal challenges, in terms of providing health and economic care to the victims and implementing preventive measures. This use of language also impacts on scientific discourse and Vajrayāna itself, and will affect many future generations.
\end{abstract}

Keywords: indoctrination and abuse in Buddhist groups; Vajrayāna; decontextualization of concepts; silencing of trauma; guru yoga; pure view; karma purification; crazy wisdom; mindfulness; trauma

\section{The Inflation of Vajrayāna}

Recently, severe damage to health has been reported in Vajrayāna groups, due to economic, physical and psychological abuse. It is the testimonies of witnesses and the victims themselves that reveal a covert attitude of personal enrichment and self-centeredness on the part of authorities and their entourages in painful detail. While the narrative of Vajrayāna (Patrul 1998, p. 440) as being a quick path to enlightenment, and the expansion of the Dharma with Tibetan Buddhism spreading to the West, has continued, quality of care has vanished at the expense of the quantity of centers considered as status symbols. The pattern of euphemisms for the retrospective glorification of religious authorities has become interrupted by those affected joining to begin to share their own stories of indoctrination, exploitation and abuse. This signifies a turning point in the historiography of Tibetan Buddhism. Unlike the structures and hierarchies defined in Buddhist monasteries, which were copied unreflectively into Buddhist seminar and retreat centers, the strategy behind establishing huge amounts of international centers involved appointing people who quite often were uneducated about their 
positions. They then established undemocratic group structures along with their masters, served their hidden agendas, and promoted decontextualized concepts. At present, that decontextualization of terms can no longer be separated from the silencing of trauma and a linguistic style rationalizing this. It has been facilitated by replacing the clear definitions of technical terms of Buddhist philosophy with an oversimplification of concepts, together with illogical reasoning, replacing logical conclusions with blind faith. In this way, neologisms, distorted concepts and selective quotations are now promoted as Buddhism. While an introspective, self-reflexive attitude, and the knowledge of Buddhist philosophy being an instruction for the individuals' path to autonomy were lost, the identification with teachers (Anders 2019a, p. 35) and one's own group were widely propagated as mainstream instead. The monetary inflow and prevalent tendency towards naively idealizing Buddhist ideals once seemed to prove the established position-holders and their entourages right, despite their ignoring the realities of people in those groups or suppressing their expression. But, over the years, enrichment based on massive processes of exploitation and submission, especially towards the feminine, and the depersonalization of group members, leading to economic, physical and psychological abuse, became evident. Beyond that, however, neologisms such as the concept of 'karma purification' were developed, meaning one person purifying another's so-called 'bad kama,' or even part of his group implementing such an idea at his command. This reveals a strategy of masking human exploitation and traumatization by using spiritual guises and every available means to achieve concealment. As "all the perpetrator asks is that the bystander do nothing [ $\ldots$ and] appeals to the universal desire to see, hear, and speak no evil" (Herman 2015, p. 7), these new rationalizing concepts have been supported by irresponsible authorities, making it even more attractive to "take the side of the perpetrator" (Herman 2015, p. 7) or obey his orders, which, in such contexts, was even referred to with the term 'devotion'. Now that we are facing its impact on the group dynamics of people played against each other, and on the health of individuals leaving such groups, the question arises of how these mainstream misconceptions designed to silence the unspeakable (Herman 2015, p. 1) could ever be reversed, and their damage minimized inside as well as outside the established structures. Thus, the inflation of knowledge transmission of the Vajrayāna came about due to simplified concepts, suitable for the purpose of commercialization and manipulation, and the associated decontextualization of technical terms (Anders 2019a, p. 35) used in Buddhist philosophy and Tibetan medicine, which were then intermingled, ignoring their unconscious aspects, and used to silence trauma. In addition to significant damage to the health of the long-term practitioners and those students, who abandoned a lot in the process of becoming involved, or were severely exploited and then exchanged for others, this has resulted in severe disappointment, due to misguided spirituality. In such settings, the misinterpretation of devotion (Anders 2019a, p. 37; Kongtrul 2003, pp. 63-64) as blind trust is just one of the manipulative methods applied. Furthermore, the unconscious devaluation of the feminine in this context, which allows one to project one's own unwanted fantasies onto those who are denied their own voice, leads to the unimaginable social isolation of the affected girls and women, which is supposed to condemn them to speechlessness and being forgotten. These painful ways of silencing were explained for the circumstances of traumatization by Herman, as follows:

In order to escape accountability for his crimes, the perpetrator does everything in his power to promote forgetting. Secrecy and silence are the perpetrator's first line in defense. If secrecy fails, the perpetrator attacks the credibility of his victim. If he cannot silence her absolutely, he tries to make sure that no one listens. To this end, he marshals an impressive array of arguments, from the most blatant denial to the most sophisticated and elegant rationalization. After every atrocity one can expect to hear the same predictable apologies: it never happened; the victim lies; the victim exaggerates; the victim brought it upon herself; and in any case it is time to forget the past and move on. The more powerful the perpetrator, the greater is his prerogative to name and define reality, and the more completely his arguments prevail. (Herman 2015, p. 8) 
The following text will address the ways of silencing trauma in Vajrayāna contexts, by describing some crucial aspects of rationalization with seemingly Buddhist terminology and the psychological mechanisms of projection, subtle shifts and double bind. However, these psychological proceedings, manipulations and tricks are not regarded merely an individual issue, as they are commonly devalued into individual perception in such contexts. They have extensive implications for the Buddhist groups themselves, society and knowledge of Vajrayāna. When spiritual authorities dictate terminology to silence their victims and thus manipulate their own followers, their students also learn how to view and rationalize such issues, and how they are expected to deal with victims. In order to comply with the rules of silencing, friendships collapse, and people turn against each other. Fear is methodically introduced through these means, and victims are deprived of the most important and protective measures of social contacts. Therefore, with such methods, even natural compassion towards the affected ones becomes suppressed. This suppression works with confusion at the psychological level and, in such a way, freezes decisions and the natural impulse to protect people. It also works by instilling fear, which is imported with talk about the hells and the unwanted, and often an unconscious avoidance of exclusion from the peer group. Thus, the current situation clearly reveals the extent to which recent developments have already deviated from the traditional purpose of Vajrayāna, its core of bodhicitta (Coleman and Jinpa 2008, pp. 588-89; Dalai 1992, pp. 207-8; Köttl 2009, p. 160; Richard and Vivian 2010, p. 7; Tsepak 2003, p. 183), as well as its practice of taking the goal as the path. Considering the impact of the elevating irresponsible people, without considering the impact of their behavior on group dynamics, society and their victims, one might raise the question of the minimum requirements for education and leadership qualities of such spiritual authorities. It is these developments that make clear how Vajrayāna's heart of bodhicitta was lost.

\section{Implications of Losing the Heart of Vajrayāna}

The Vajrayāna, as it is handed down in Tibetan Buddhism, has been considered an individual path of training based on its core of compassion and bodhicitta, which are cultivated throughout several sequential levels from the very beginning of individual training. Based on authentic bodhicitta, Vajrayana's method of using the objective as the path is also known as the rapid path, compared to other Buddhist practice paths. Thus, vital for all its methods is the formation, differentiation and improvement of these very core qualities within the trainee. As indicated by the syllable rgyas of the Tibetan term for Buddha, sangs rgyas (Köttl 2009, p. 14; Tsepak 2003, p. 282), it is said that these very aspects would have consequently fully unfolded (rgyas) at the objective of complete enlightenment. The Tibetan philosophical texts and Oral Instructions accurately describe the preconditions, preliminary activities (Coleman and Jinpa 2008, p. 706), key aspects of training, stages of maturity, as well as any possible dead ends. Furthermore, the genuine accessibility of the Vajrayāna training is said to depend on an inner maturation process, which leads to a certain kind of insight. That insight itself is defined as the very first moment of the path of seeing (Attersee 2014, p. 46; Tsepak 2003, p. 129), and is said to initiate the first bhūmi (Attersee 2014, pp. 29, 49; Dudjom 1991, p. 166; Köttl 2009, pp. 32, 210; Tsepak 2003, p. 278). Thus, it is precisely this individual insight constituting the first bhumi that initiates the path of seeing and, thus, impacts on the main methods of training. Therefore, for Vajrayāna practice, several conditions are required in terms of personal development and maturation, all the way up to a certain type of insight, which is referred to by the term śunnyata (Attersee 2014, p. 19; Coleman and Jinpa 2008, p. 641; Köttl 2009, p. 211; Tsepak 2003, p. 113). This also means that this insight, referred to as śūnyatā, is an imperative condition for Vajrayāna. Consequently, understanding of that perspective refers to an inner process that is furthered through the process of individually working with the subtle aspects of awareness, referred to as non-meditation (Attersee 2014, p. 19; Köttl 2009, p. 167), because focus can be increasingly diminished by the trainee. In the absence of genuine insight, however, the practice of visualization itself, which is addressed with the practice of a development stage and completion stage (Coleman and Jinpa 2008, pp. 609, 649; Dudjom 1991, p. 108; Köttl 2009, p. 22; Tsepak 2003, p. 261), is merely an artificial construction. This means that the core 
methods of training for the path of seeing will not make sense for anyone who has not yet arrived there, because the person lacks understanding and, along with that, knowledge of when to apply the respective tools. It is precisely this individual, non-accelerative insight which is linked to the accurate comprehension of certain concepts in that context, such as what is often translated as pure view (Anders 2019a, p. 38; Coleman and Jinpa 2008, p. 662; Kongtrul 2012, pp. 124-73) or authentic view. As the approach thus depends on an internal, subjective level of insight, it is to be interpreted from the perspective of the practitioner. Then, the light of visualzsation is rather the quality of the experience, as opposed to any construction of figures for identification (Anders 2019a, p. 35). It has been said that, in the absence of that genuine insight, the practice of visualization itself is merely an artificial construction. This means that all teachings on the view are to be interpreted not only before understanding of their background of the lineage, but taking into account the perspective of the listener, who is limited to his or her understanding. Based on this, presenting a new object of focus called 'pure view' is misguiding and irresponsible. Prescribing 'pure view' as a kind of positive thinking leads to manipulation and distorts the meaning of Vajrayanna. Hence, the currently circulating mainstream meaning of the phrase 'pure view' differs to such an extent from its original meaning that it may already be considered a kind of neologism. That is, currently employed decontextualized key phrases, such as 'pure view', 'karma purification' and 'crazy wisdom' (Anders 2019a, p. 37), are used for manipulation and obedience to such ideas has rendered people sick. Therefore, the next chapter is on the role of, and qualifications for, a spiritual teacher.

\subsection{The Role of the Spiritual Teacher in Vajrayāna}

Generally, a teacher-student relationship (Coleman and Jinpa 2008, p. 678; Patrul 1998, pp. 137-66; Kongtrul 1999, 2003, pp. 39-77) can be built at many levels, depending on the training intended (Kongtrul 1999, pp. 55-62, 139-43) and the qualification of the teacher (Kongtrul 1999, pp. 38-51, 126-36). Traditionally, it is meant to facilitate the transfer of knowledge and blessings. The spiritual relationship is, therefore, in the learners' best interest and intends to enhance the individuals' spirituality and autonomy. As this relationship deteriorates easily if other interests, such as financial concerns, positioning or sexuality are involved, it is to be protected. Although the teacher is particularly responsible, due to the unequal balance of power, the protection of this relationship requires consideration on both sides. Impressed by imported foreign-language mystified honorary titles (Berzin 2010, p. 13), and taking no time to study and reflect on the ways of examining one's teacher (Kongtrul 1999, pp. 52-54, 137-38; Patrul 1998, pp. 137-66) as transferred through classical Vajrayāna texts and their translations, but longing for what is said to be the quick path to enlightenment, the setting of ethical and legal standards was neglected in many Buddhist groups and societies. This is what we, and many future generations, now pay the price of. Whereas social control was effective in that respect, and the behavior of teachers was observed and judged in ancient Tibet, nowadays mainstream attitudes and behaviors result in super-elevating people who claim spiritual honorary titles, unreflectively allowing them anything by labelling their actions as 'crazy wisdom'. Thus, having built relationships in Buddhist centers based on power imbalances, in the progress of training, dependencies (Anders 2019a, p. 34), rather than individual maturation and developing autonomy, increased. The process of subjugation on the part of the leaders, and submission on the part of the students, has led to traumatization. Due to missing knowledge of the unconscious and its implications, and of psychological trauma treatment in Buddhist philosophy and in Tibetan medical contexts, this traumatization was ignored. Even worse, instead of listening to victims with genuine compassion, the highest authorities regard and proclaim the damaged ones to be aggressive. In this way, they not only ignore the long-lasting effects of psychological trauma on the individual as well as the group, but publicly stoke the aggression that has harmed the victim. In that context, one particular risk in preventing clarity and accountability lies in the lengthy endurance of the confusing double bind (Anders 2019a, p. 35). In this way, the concept of the teacher-student relationship, as taught in traditional ancient texts, and the practise of guru yoga, has become utterly meaningless. 


\subsection{The Method of Guru Yoga and Its Current Distortions}

What has been translated into the phrase pure view was once a clearly defined philosophical technical term, used for a very specific concept of individual insight. Understanding of its meaning is, therefore, bound to this very insight, in the sense of the individual embodiment of bodhicitta and a very specific training based on that, which is elaborated on by different philosophical schools using their own traditional terms and connotations. Without that insight, the meaning of pure view, and explanations connected to it, cannot be captured, and, thus, there will be a lack of understanding, even when hearing the terms, just as children who are about to learn letters are not yet able to read a book and understand the meaning of its words. Based on an introspective, self-reflexive attitude and on gaining such insight within oneself, the method of guru yoga (Anders 2019a, p. 36; Berzin 2010, pp. 133-45; Patrul 1998, pp. 309-47; Richard and Vivian 2010, pp. 60-68) implies blessing from a qualified master, in the sense of the transmission of blessings from the lineage of those who have implemented the theoretical knowledge, in an individual and lively unfolding of compassion and bodhicitta. The blessing itself is furthered by the aspect of devotion (Tsepak 2003, p. 131) to one's own path, the meaning of the teaching, and the lineage of those who have embodied the knowledge within themselves, involving an internal introspective and self-reflective attitude that is a vital part of their lives, going far beyond the acquisition of mere words and concepts. In order to use Vajrayāna techniques, there are conditions for teachers as well as disciples-abiding by unwavering ethics, the unfolding of bodhicitta and the authentic realization of śunyatā are true for all its visualizations. This may then serve as context for the combining of visualization of a buddha of light with the lineage of blessings, which is referred to as guru yoga, and performed by merging the buddha of light in one's visualization with the last person in the lineage. These clearly defined concepts largely differ from what is conveyed and understood by the audience when commercializing Vajrayāna. Furthermore, as narcissists have been attracted by the concept of visualizing oneself as a Buddha, omitting the key element of light, it was just a matter of time until the meaning of terms and phrases was conceptually distorted. In such distorted contexts, however, the visualization of the completion stage in particular tends to be misunderstood and used for self-elevation, or even an expectation of constantly merging on the side of a teacher, or anticipatory obedience on the side of a student, in this regard. The latter has been described by Rigpa students as "we failed to 'tune into your mind' and predict what you wanted" (Standlee et al. 2017, p. 4), showing the manipulation into constant merging. After many years of such training, this mental pattern hinders self-responsibility and autonomy in students, and challenges the cure of trauma and mental diseases. This makes it especially difficult to differentiate between one's own self and the introjects, which is essential for the process of recovery. Thus, nowadays, we face the dynamics of manipulation, and putting people on the hook of dependency under the guise of Buddhist spirituality. Furthermore, personality cult (Langel 1995, pp. 131-34) practices have been introduced to students for so-called 'guru yoga' (Anders 2019a, p. 36; \#OKCinfo ex-OKC born-kids, slide 25). Against the background of cultivating one's own narcissism, or suppressing and silencing trauma, this loss of meaning is accompanied by several psychological manipulations. The expectation of strict obedience is presented through selectively presented rules of observing vows. Usually, these are about maintaining the authority of the leader, and, for the sake of simplicity, they are again explained using pure view. The selective imparting, and omission, of basic information is also striking. This raises the question of whether inadequate information can be seen as a further tool for increasing uncertainty, dependency and fear. Threats of the 'vajra hell' (Baxter 2018, p. 15), referencing samaya, and the corresponding paralyzing and stigmatizing effects on group dynamics are obvious and need to be analyzed against the background of the trauma dynamics and stigmatization of those affected. This discourse, in which basic conditions, such as thorough information prior to contract and lapse of contract if one side does not comply, are ignored, illustrates very well how requirements from above are internalized, without allowing for the ability to dissociate oneself, even after separation from the group, which is further reinforced by the above-mentioned merging practices. Particularly, it is these instances of intimidation, and the structural implementation of the manipulation of people, that bring such systems of thought 
into the proximity of cults (Hassan 2018). But, since these challenges cannot be solved individually, analyses of the underlying structures and of the complex interrelations promoting such incidents are required, without disregarding the need for immediate prevention of such practices, and urgent relief for those already affected. The following passage may clarify how far Vajrayāna has deviated from its core by now:

Please understand the harm that you have inflicted on us has also tainted our appreciation for and practice of the Dharma. In our decades of study and practice of Tibetan Buddhism with you, we trained our minds to view you as the 'all embodied jewel' and the 'source of all the teachings and blessings' of the Buddha-Dharma. We trusted you completely. Yet, we struggled for years because your actions did not square with the teachings. Today, for many of us who have left you, the Lerab Ling community, and Rigpa the organization, our ground of confidence in the Buddha-Dharma has been compromised. Some of us, who chose to depart abruptly Lerab Ling, left all of our possessions, because we were desperate to break away from your abuse and the community that supported it. [ ... ] Whether we departed abruptly or have faded away from you and Rigpa, we struggle to rekindle an appreciation for the transformative teachings and teachers we encountered. (Standlee et al. 2017, p. 7)

In reviewing teachers, ensuring that their actions correspond with what they teach is a core factor, and it is said the actions of sages are refined, or differentiated, like barley flour. Corrupt Dharma, however, presents as cruel behaviour, covert objectives, lack of transparency and a double bind of authorities and their entourages. Clinging to self-interest is said to be far from the attitude of a bodhisattva (Gyalchok and Gyaltsen 2006, p. 558) and, in that way, one is even losing the necessary conditions of Vajrayāna attitude and practice, as such behavior is the opposite of the basic practices condensed as "parting from the four clingings" (Gyalchok and Gyaltsen 2006, p. 525). Together with the silencing of trauma and its victims, the commercialization of Vajrayāna has now led to the concealment of personal interests. This shows in its highly confusing structural, terminological and psychological issues.

\subsection{The Narrative of Physical Closeness to One's Guru Being Interpreted a Sign of Having 'Good Karma'}

The commercialization of any meditation techniques attributed to Buddhism, and attempts to make use of them without ever having studied them in their original language contexts, lead to the development of international substructures. Many of the large numbers of people attracted to these strive towards reaching positions within these organizations, which are often described as a particular physical closeness to the teacher, or towards income-all of which is covered and concealed by a spiritual cloak. Although the narrative of striving toward positions within spiritual groups is explained as a special closeness with the teacher and his agendas, the intermingling of interests already diverges from traditional texts, where the foundation and necessary condition of Buddhist practise is explained by the basic attitude of going beyond worldly concerns. As this attitude is the benchmark dividing between spiritual and other paths, there is no spiritual path which includes working for one's own positions and profits, regardless of whether one is in an international Buddhist center, which is described as a good way to identify with the projects and goals of one's guru, or anywhere else. Therefore, this mainstream habit of rationalizing closeness to authorities in the sense of a demonstration of 'good karma', often intermingled with one's own position in any spiritual group, is a trap in the path itself and a dead end - the effects of which have become obvious by now. Furthermore, people being played against each other, in the light of the new narrative about the physical closeness to any master and the frequency of meetings, has paved the path for abuse at all levels. Contrary to that, in the traditional texts, one was taught to rely on the teachings and not an individual (Kongtrul 2012, p. 68). Thus, the spiritual path itself was regarded as a highly individual process towards autonomy. And, far from the meaning of the term karma (Kongtrul 2012, pp. 184-91), within traditional Tibetan 
texts of Buddhist philosophy, such 'good karma' demonstrations, by means of striving for positions and physical closeness to a supposedly spiritual teacher, have increased the building of hierarchies and covert rivalries among group members. Furthermore, simplistic conceptual implications that others, who are not running after such issues, have any 'bad karma' and even ought to be 'purified', were employed. As conceptualizing one's own sublimity goes along with identification and giving up one's self-responsibility along with that, this not only furthers arrogance and increases narcissism, but serves to cover up dysfunctional group aspects and is critical when it comes to one's own progress on the path. This issue impacts not only on the individual, but also on the Buddhist group, other groups of (Tibetan) Buddhism and society. Therefore, in addition to relying on traditional procedures to examine the qualifications of a teacher (Kongtrul 2003, p. 42), these need to be updated to meet the current societal challenges, especially regarding attitudes of exploitation towards women.

\subsection{Structural and Terminological Issues in Developing Power Imbalances}

Downgrading introspection in the value scale of Western cultures (Attersee Anders 2016, p. 11) for long has resulted in an uncritical incorporation of ideas seemingly satisfying this need. Therefore, the longing for introspection (Attersee Anders 2016, p. 11; Attersee Anders 2017, p. 14) has been approached through the uncritical and unreflective adoption of social hierarchies and power imbalances accompanying so-called Buddhist meditation. This has led to the commercialization of any meditation techniques attributed to Buddhism and attempts to make use of these concepts without ever having studied them in original language contexts. The statement of one of the probands, saying "below the surface it looks different than at first glance" (respondent \#1), reflects the structural and terminological challenges one faces when looking below the surface.

\subsubsection{Structural Challenges}

In recent decades, feudal structures (Anders 2019a, p. 35; Finnigan and Hogendoorn 2019, p. 139) and hierarchies of power imbalances have been copied unreflectively from Asia to Europe in the name of Buddhist spirituality, teaching and training. The strict hierarchical organization in international Tibetan Buddhist organizations teaching Vajrayāna supports maintaining the power of a particular lineage, in terms of combining secular with spiritual power, just as in ancient Tibet. The silencing of abuse victims is enforced more swiftly in such structures, thus serving to silence trauma. Besides strictly hierarchical command structures, a covert attitude of exploitation can be observed, especially towards the feminine. And although their financial gains long seemed to justify the strategy to disregard both the traditional and the contextual procedures of teaching certain techniques only to prepared people, the high price we all pay for it now shows. The opinion of some masters and their entourages to be beyond the law of the countries they are in, together with their disregard for the Convention on Human Rights, especially Women's and Children's Rights, currently present society with particular challenges. Society must compensate for the costs of those who have become chronically ill as a result of exploitation, stigmatization and trauma, and the respective burden of isolation and silencing that they carry. Particularly, since the feminine was not only devalued, but considered an exploitable mass to be controlled, this type of knowledge transfer and business, in recent decades, was performed at the expense of many women. After the disclosure of the first cases testifying abuse, we reached a point where these once seemingly flourishing centers of international Buddhist organizations in many countries have turned into religious as well as societal challenges, instead of an individual issue. In order to illustrate these circumstances, quotes from testimonials, as well as statements from probands, which are taken from the current research project (Anders 2019b, 2019c), will be presented in the following text. People from different countries, who learned about my research project through word of mouth or social media over time have requested the questionnaires via email. The links to the English or German version of the questionnaires were sent to the participants, together with an individual TAN via email. In this way, they could be pseudonymously filled and submitted in protected places. Thus, even when participating in the study on health in Buddhist groups, there 
is a distribution that reflects the tabooing in groups on the one hand and tremendous distress of those affected, who have to fear for their safety and sometimes their lives. It is currently evident that filling out the questionnaire in safe places using a pseudonym was used by some people as a medium of, and a cry for, help. At the same time, however, there is also information indicating that severely traumatized people require therapeutic care urgently and, due to triggers when writing, cannot complete the questionnaire at all. The probands wrote from their experiences in international so-called Buddhist organizations-many of which have a huge number of centers in many countries, which increases and complicates the issues addressed, and renders legal procedures and necessary victim compensation almost impossible. The number of centers may indicate a large number of directly and indirectly affected individuals, seminar attendees, workers and their children-not all of whom are members. Someone who stated that he was part of the Zen-Suzuki groups in Germany and different Tibetan Buddhist groups such as the Rangjung Yeshe Gomdes, Drikung and Rigpa Centers described his experiences as follows:

I found this mixture increasingly unacceptable. Glorifying attitudes, struggling for recognition, power over others and striving for top positions, under the carpet of niceties and hugs, denying and suspending unpleasant truths, neurotic devotion to a strictly hierarchical and non-transparent system that confuses spiritual devotion with self-abandonment. It was quite striking how easy it was to manipulate the vast majority of the participants, most of them were actually waiting for what I found to be a consequence of a lack of genuine personal responsibility. Even teachers unwilling to create such manipulations were wrapped up in a web of what I call 'sangha-show'. Unfortunately, they do not seem to understand this. Often enough with a feeling of being at the pinnacle of evolution to be able to teach others. In the vast majority of groups, I found little room for what I consider to be genuine practice, which I believe to imply an ability of being honest with oneself, but instead any other substitute activities, concealed by incredible effort of pretending to be advanced already. (respondent \#1)

The manipulation described above is masked by a conglomerate of seemingly Buddhist terminology and the formation of stereotypes (Anders 2019a, p. 34), within which hidden agendas are communicated. Besides the resulting self-deception rendering one's own path a dead end, this is the context for double bind, causing severe diseases after years of exposure. In the international Buddhist groups, hierarchies, similar to the ones in Buddhist monasteries where women are ranked below the youngest of monks, as well as the level of physical closeness to the master, are considered important ordering principles. Whereas the former corresponds to the working and command hierarchies, the latter is spiritually connotated, constituting an inherently risky conceptual connection between sexuality and spirituality. These two structures may overlap, and what was called the 'inner circle' in the organization Rigpa might well have other names in other organisations, e.g., Kusung in the organization Shambala. Baxter outlined the implications of these structures as follows:

Individual experiences are very different. There are varying degrees of closeness to Sogyal Lakar, with the closest relationships regularly referred to as the 'inner circle'. The experiences of some of the members of the inner circle are very different from the experiences of many of those who are less close. [ ... ] a. some students of Sogyal Lakar (who were part of the 'inner circle', as described later in this report) have been subjected to serious physical, sexual and emotional abuse by him; and b. there were senior individuals within Rigpa who were aware of at least some of these issues and failed to address them, leaving others at risk. (Baxter 2018, p. 4)

Thus, at this point, the aspect of silent testimony has been touched upon. In the following subchapter, some core aspects of terminological challenges will be addressed. 


\subsubsection{Decontextualisation of Terms and Concepts}

Whereas the word-by-word commentaries on Buddhist philosophical texts in Tibetan monastic education focus on explaining the meaning of terms and context for the purpose of one's own autonomy on the path of training, translations disregarded these differentiations, as well as existing semantic connotations in the corresponding languages, whilst commercializing Buddhist spiritualty. Thus, the decontextualization unfolded, ascribing new, simplified meanings to terms. Particularly, beyond clear definitions, differentiated use of language and logical conclusions, the understanding of meaning became more difficult. Thus, an understanding of meaning that goes beyond a mere repetition of terms was lost. In particular, an inability to understand introspective patterns and establish true self-reflection based on them, and the fact that teachers no longer teach from experience, means a loss of conveyed meaning-that is, the prevailing concepts ascribed to Tibetan Buddhist philosophy and Vajrayāna practice have little to do with what was taught in original language contexts. Furthermore, the current wording has been used to disguise the facts of abuse for decades. Therefore, allowing the painful naming of those issues, and listening to those concerned by indoctrination and abuse, will be a step towards urgently needed change. Depending on the victim's personality and the damage suffered, these expressions may vary. We have seen this naming of facts in the open letter by eight people from the organisation Rigpa, saying "we now see clearly the many ways that you betrayed our trust, manipulated and abused us and our Dharma brothers and sisters" (Standlee et al. 2017, p. 7) and in many other groups, as well. Concurrently, we can observe the stigmatization and silencing accompanying this, not only by the groups themselves but also by Tibetan authorities, particularly the instillation of fear of losing a 'pure view'. In early stages of counselling and treatment of the people affected, issues of isolation, stigmatization, silencing and fear are crucial. It is due to these issues, that people have committed themselves to secrecy to this day. Furthermore, if this secrecy is violated, some of them are threatened with methods of slander and social isolation. In particular, the perception (Anders 2019a, p. 39) of critically minded individuals and abuse victims has been systematically questioned, while they, at the same time, have been socially isolated (Anders 2019a, p. 39). One person from the organisation Rigpa described this as follows:

With Rigpa: Refusal of any discussion on the part of Rigpa, I felt the situation to be hopelessly stuck. My person as a critic was accordingly ridiculed, portrayed as psychologically 'strange'. Usually this happened with most 'dissidents', that was one reason to go, some form of ethics was completely missing. Right was what was in the mind of the master or what was thought to be so. One could call it a general refusal to engage in dialogue. Other organizations: Even if the lama is okay and doesn't abuse students, unfortunately there are always various phenomena: worship of the lama in a western, blind and seemingly naive way, completely intransparent structures regarding money, power, ways of decision. Fixation on career in the ranking in the 'Sangha'. Willing adaptation of authoritarian structures. Those who don't want to or can't fit in will fall out sooner or later, the social pressure is often subtle but very high. Mixing of the whole sub-cultural mishmash of hippie, New Age small ideologies, green alternative behaviors with the traditional ballast from Asia: feudalistic structures, special hierarchies, outdated interpretations, etc. [sic.] Efforts to mix psychological methods with Buddhism. (respondent \#2 in Anders 2019b)

Due to the use of stigmatisation and slander as a threat (Anders 2019c) against group members, and, in this way, destroying their wider social and professional resources, it is not easy for members to distance themselves from such organizations, as was shown, for example, with the statement "you have encouraged us to defame others, in particular in France, who have spoken out against you in recent years" (Standlee et al. 2017, p. 8). At this point, counselling, particularly concerning legal and social protection and sorting out the double bind members are caught in, can help people to leave cruel groups in a timely manner and, in this way, also prevent the development or chronification of mental diseases. It is the combination of a personality cult (Anders 2019a, p. 34), together with the phrase 
'crazy wisdom' and the neologism 'karma purification', that allows for violence and irresponsible deeds on the part of the leaders and their followers. That is, people are taught to believe they have to suffer abuse to have their so-called 'bad karma' purified (Anders 2019a, p. 39). Thus, actual reality widely diverges from the idealized picture or projected ideas of healers (Anders 2019a, p. 37). Whereas the master of the narrative would be allowed arbitrariness without any consequences, due to having been attributed with uninterrupted access to 'absolute truth', other people's perceptions are systematically questioned. They get used to being told that they have the 'wrong perception and view', because it is inconsistent with the authority's. Thus, this narrative traps people by setting 'purification' as an impossible standard (Hassan 2013, p. 16), with shame and guilt at its core, while assuming any 'master' would be in a position to 'purify' their 'bad karma' and conceptualize his group as being allowed, or ordered by himself, to do so. This new kind of group manipulation, called 'karma purification,' serves to justify violence and abuse against individuals. This is supplemented by a denial of self-responsibility, and the constant merging of one's mind with so-called spiritual leaders, which is referred to as ' $g u r u$ $y \circ g a^{\prime}$. Apart from this kind of mind control, group pressure imposes various stereotypes regarding how a good Buddhist is supposed to speak and act. The very compassion that was once defined as a clear sign of the effects of authentic, correct practice, is absent in so-called teachers manipulating and abusing their followers. It is the ambiguous two-faced reality they create, with ideal images to which people are required to adapt to, which in turn binds them into such systems of exploitation and abuse. That is, due to their longing for the quickest path to enlightenment and chasing of promises such as enlightenment in one lifetime, people are made to pay for a growing number of seminars which supposedly lead to this. Instead of gaining access to their own spirituality, however, they are drawn into a net of dependencies and devaluations. Thus, although Vajrayāna has both compassion and bodhicitta as its central premise, it is these very qualities which have increasingly disappeared. Within these new narratives of Vajrayāna Buddhism, the victims themselves are even being blamed for the harm they have suffered, stigmatized and excluded. These actions of wounding and secondary wounding speak for themselves. Now that their reputation and structures are at stake, it has become evident that the secrecy and silencing these organizations have enforced has not done them any good.

\subsubsection{Confusing Concepts}

The new terms and meanings ascribed to Buddhist practise served to conceptualize risky relational structures and double bind, covering the entire system, which is confusing, because any action one chooses may be interpreted as the wrong choice. Double bind may show in many ways, for example in the discrepancies between the public and private face of leaders or position-holders, which were addressed in the following statement:

This letter is our request to you to stop your unethical and immoral behavior. Your public face is one of wisdom, kindness, humor, warmth and compassion, but your private behavior, the way you conduct yourself behind the scenes, is deeply disturbing and unsettling. A number of us have raised with you privately, our concerns about your behavior in recent years, but you have not changed. (Standlee et al. 2017, p. 2)

Asked why he took the decision to separate from the organization Rigpa after approximately ten years of study and work there, one person shared the following:

I saw directly that while they present a very acceptable public image behind that is a lineage of pure violence. They believe they are accountable to no one and are quite capable of taking someone's head off believing they are above any law. They also use remote viewing to injure people. One of their major teachers publicly said Tibetan Buddhism was a system that could be used by a good person or a terrorist. I have seen both sides. (respondent \#3)

The manipulation, indoctrination and abuse (Anders 2019a, p. 34) that are currently coming to light do not only impact on single individuals, but the on the group structures themselves, their group 
dynamics and the social and health systems of respective countries. Due to their questionable concepts and double bind, it stands to reason that years spent in such a system are not conducive to one's health, but are likely to impair it. Apart from the damage to health and the economic conditions of individuals, however, any groups that consider themselves and their masters to be above the law of the country are inflicting further damage. Thus, an overall rationalizing system, based on new meanings ascribed to seemingly Buddhist terminology and concepts, has evolved around these inconsistencies, attributing obvious misconceptions to the participants themselves. Concerning the ethical guidelines which are currently written for groups, one person said: "anyone or any group can make guidelines. It is actually getting them implemented that is the problem. Most large organisations, e.g., [sic e.g.,] company, religious group or government all try to hide wrongdoing as they don't want to be sued or lose reputation" (respondent \#3).

\subsection{Economical, Physical and Psychological Abuse}

The devaluation of others (An Olive Branch 2019b, p. 6), abuse of power, rumors and slander (An Olive Branch 2019b, p. 6) that were described as taking place in the organization Shambala are common behavior in many groups. When asked about the kinds of abuse experienced or witnessed, the following reply was given:

Abuse of donations, of blind devotion, of the readiness for manipulation; abuse of power or power imbalances; abuse of unknowingness and abuse of the openness to engage in other traditions; abuse of naivety and good faith. Abuse of generosity, abuse of the Dharma to sexually utilise women. Abuse of the Dharma for concealing flaws, lack of education and of realisation. Abuse of the Dharma in order to present oneself as a great teacher. Abuse of Dharma in order to aggressively release one's own negative emotions on others. Abuse of the Dharma in order to gain a position of elevation. Abuse of the Dharma in order to refuse communication. (respondent \#1)

The abuse or violence experienced in person was also described as: "humiliation, exposure, psychological violence, repression, deprivation of healthy self-esteem, intrigues, defamation campaigns, systematic manipulation and lies. Theft: [ ... ] misuse of tied donations" (respondent \#1). Concerning the organization Rigpa, the primary concerns in the open letter to Sogyal Lakar addressed the following actions of abuse: "1. Your physical, emotional and psychological abuse of students. 2. Your sexual abuse of students. 3. Your lavish, gluttonous, and sybaritic lifestyle. 4. Your actions have tainted our appreciation for the practice of the Dharma" (Standlee et al. 2017, pp. 2-3). The writers of the letter elaborated as follows:

We have received directly from you, and witnessed others receiving, many different forms of physical abuse. You have punched and kicked us, pulled hair, torn ears, as well as hit us and others with various objects such as your back-scratcher, wooden hangers, phones, cups, and any other objects that happened to be close at hand. We trusted for many years that this physical and emotional treatment of students-what you assert to be your 'skillful means' of 'wrathful compassion' in the tradition of 'crazy wisdom'-was done with our best interest at heart in order to free us from our 'habitual patterns'. We no longer believe this to be so. We feel that we and others have been harmed because your actions were not compassionate; rather they demonstrated your lack of discipline and your own frustration. Your physical abuse-which constitutes a crime under the laws of the lands where you have done these acts-have left monks, nuns, and lay students of yours with bloody injuries and permanent scars. This is not second hand information; we have experienced and witnessed your behavior for years. (Standlee et al. 2017, p. 3)

Nowadays, even harmful incidents are reframed as being the 'perception' of the individual only. This psychological trick of shifting the fault to the victim builds on simplified and distorted 
versions of philosophical discourses on the relative and absolute truth. These discourses on a view meant for individual practice are then applied to power imbalances, the manipulation of groups and the denigration of individuals. For this reframing, sometimes the terms 'illusion' and even 'hallucination' (Zopa 2019) are employed, which devalues the experience of this damage by defining it as an individual problem or even as a mental illness. This demonstrates a way of manipulating huge groups, and patterns of isolating individuals and victims, as well as silencing trauma. That is, instead of dealing with the damage, the groups have to adapt to the prescribed point of view, thought and talk. Thus, unwanted aspects are pressed into the unconscious. That perspective was then spiritually masked and promoted as a so-called 'pure view,' which people are manipulated to adopt, especially by inducing the fear of 'creating bad karma' through naming the incident or speaking up. In addition to this structural silencing of victims, they are stigmatized as 'having a bad karma' and patterns of ignoring or even excluding them from the group lead to secondary wounding. Thus, based on the distorted concepts described above, the 'reality' or 'truth' is defined by the abuser and his entourage, by prescribing the way of thought for the group. Thus, the damaging incidents remained hidden for decades, by stigmatizing victims and ignoring the harm endured, instead even framing it as beneficial in the sense of the assumed purification of their 'bad karma'. Furthermore, the exploitation of those working in such a Buddhist organization was described as follows:

I tried to be cheerful and accommodating within reason, but they expect way too much from people. At a certain point after working between $8-10 \mathrm{~h}$ or if I got injured, I started telling people I was going to bed. They looked shocked like someone slapped them. Those who worked to exhaustion were seen as the most devoted until they could no longer complete tasks. After I threw my back out building the foundation for the lama's cabin, I refused to do work that would harm me physically (I already had back problems from excessive manual labor during formative years in foster care). (Anders 2019c, respondent \#4)

These statements, made by people from the 'inner circles', bear far-reaching implications, as became apparent with the letter of Kusung (Morman et al. 2019), in the organization Shambala, because they show the layers and strategies beyond the public, nice face of the organization. The survey questioned whether one's own education and training was taken into account when being selected for a job in the Buddhist group. One of the answers was: "they treat everyone as an underclass of servants that exist to serve the lama" (respondent \#4) and the person explained further "it was based on what the lama decreed. Almost everyone obeyed like slaves" (respondent \#4). Thus, in such structures, the devaluation and exploitation of others, using very well-trained people as slaves for one's own purposes is regarded as normal. The extent of the damage inflicted on the person concerned, and its impact on his or her life, is only revealed when listening to his or her narrative, which is not taken seriously in current Buddhist discourses. Here is an example:

I separated from my first guru (from the now-defunct Ratna-Shri Drikung Kagyu center in Berkeley, California) because he sexually violated my best friend. The lama chose her because she was mentally ill and had a history of abuse. He told her he could heal her trauma through sexual acts. I separated from another center and lama (Dzogchen/Nyingma) in Oregon because students were being worked to exhaustion, financially exploited, and discarded. They were told if their minds were pure, they would not need much sleep and their bodies would not get injured from backbreaking labor. People were told the world was ending and they should use their credit cards and savings to make donations because the merit they would get would be incalculable. This place was run like a cult. The teacher also was very controlling and made homophobic comments. [ ... ] One of the students worked so much, she had a nervous breakdown and ended up in an institution. No one from the sangha visited her and they banned her from the center I practiced on my own for years after this until [ ... ] after I discovered that my best friend's child had been raped by the lama/tulku Shenpen Rinpoche, in addition to other children. I had been struggling with my faith for 
years prior to this [ ... ] I could no longer represent an organization or faith that did this as a monk. I lost my faith in Buddhism completely after seeing that the historical Buddha subjected rape victims to interrogation and expulsion if their mindfullness [sic mindfulness] during an assault was deemed insufficient. That's not compassion. I also was offended by The Buddha's misogyny in general. I don't even know what enlightenment means anymore. (Anders 2019c, respondent \#5)

Having once held a special position is by no means consolidating: "I was also declared my first Lama's regent, which meant I was expected to run his center and find his rebirth when he died. I'm not looking for that pervert's reincarnation. Some work was voluntary, while a lot of it was expected or coerced" (respondent \#4). These were some of the terms and concepts used for rationalizing and silencing trauma. The reframing of the perception of group members (Anders 2019a, p. 40) by the elites, allowing them to behave arbitrarily and explaining it as 'crazy wisdom' (Anders 2019a, p. 37; Baxter 2018, p. 12; Standlee et al. 2017, p. 5), and defining harm as no-harm, caused by so-called 'good motivation', are some of the main manipulative tricks employed. The analysis of terms and concepts for the rationalization of trauma leads to group dynamics that go well beyond the dichotomy of perpetrator and victims. Some psychological aspects of this will be addressed in the following chapter.

\subsection{Psychological Aspects}

In the specific situation of indoctrination and manipulation with Buddhist terms and concepts, individuals of the entourages obtained special positions with privileges due to their physical proximity to leaders, and usually consider themselves to be above ordinary folk in a kind of spiritual narcissism. Considering the fact of the trauma dynamic itself makes it impossible to refuse positioning, tacit silence about abuse results in a positioning close to the perpetrator. For these individuals, this constitutes a narrow path dividing privileges and their own subjugation and self-abuse. Simultaneously, they themselves are bystanders and witnesses, whose positioning, which they rarely seek, is challenged, because of their identification with the perpetrator, or because of a more or less conscious fear of being victimized themselves. Some even take on the role of teachers indoctrinating the group by unreflectively adopting the previously described concepts and, thus, stigmatizing victims and isolating them socially. Now that the realities of indoctrination, and the current circumstances of economic, physical and psychological abuse (Anders 2019a, p. 39; An Olive Branch 2019a, p. 7; 2019b, p. 6; Standlee et al. 2017, p. 3; Baxter 2018, pp. 16, 23, 29; Finnigan 2019; Winn 2018, p. 5; Winn and Merchasin 2018a, p. 6; Winn et al. 2018b, p. 6) are emerging, it would be appropriate to use courage and strength to thoroughly restructure organizations, to compensate victims and to prevent further damaging incidents rather than whitewashing them, which only the established elites and entourage, who have already profited at others' costs, would benefit from. Although such ensuing damages are inconsistent with even the basic Buddhist assumptions of non-damage, they continue to be rationalized by its elites, who try to reframe their subordinates' perception and, in these ways, put group pressure on them, in favor of their own agendas. When it comes to trauma (Newland 2019, p. 213), the agenda is to silence and isolate the victims, and deprive them of people who simply listen, which deprives them of the urgently needed social networks to prevent the outbreak and chronification of disease. While employing the same, dubious terminology, group members, who have not only witnessed the abuse, but often enriched themselves in the role of teachers, translators and command-takers for very many years, continue to preach their versions of 'pure view', the 'karma purification' of others and Buddhist meditation on such grounds. This means that the instructions of such teachers cynically preaching a 'pure view' that whitewashes abuse and exploitation and regards the victims to be the objects of so-called 'karma purification' are not only stigmatizing those affected by abuse, but are also continuing to manipulate their seminar participants. Whoever is chosen as an object of that 'purification' is not only covered with projections of the unpleasant elements of the projecting group, they are made into the object of acts of slander, stalking and bodily harm. This frequently results in multiple and complex traumatizations and secondary traumatizations. These are the consequences 
of ignoring the individual and collective unconscious (Hark 1988, pp. 188-89), the discourse of which has permeated scientific fields and social contexts in Europe and America for more than one hundred years, and promoting identification with the collective psyche (Jung 1990, pp. 53-59), instead of updating knowledge and teaching in a culturally sensitive way. Thus, the prescribed ways of thinking, talking and reframing push people into being objects of the group unconscious (Jung 1990, p. 59). This shows in the fact that, while consciously preaching their understanding of compassion, many of the group members are quite unconcerned by the pain and damage inflicted on the victims. Although, at this point, an urgently needed dialogue could be developed, respected authorities dictate to others how they should feel and think, reframe the trauma as aggression, and, in this way, work towards collective silencing. In such ways, the victims are subjected to the projection of many unwanted aspects of the group. It is the power imbalances (Baker 2019, pp. 85-89) within the structures of established centers that facilitate this. Although it was said in Buddhist teachings that genuine teachers were able to explain and impart knowledge through their own understanding and insight, and that their behavior would grow increasingly refined, it seems that nowadays we instead see the repetition of fancy and nice-sounding words. Both the victims and their society pay a high price for this. Furthermore, some individuals were subjected to pseudotherapies (e.g., 'Rigpa therapy') (Anders 2019a, pp. 34, 42; Standlee et al. 2017, pp. 4-5; Baxter 2018, pp. 31-32) in their Buddhist groups, which impacts negatively on their trust. As in many countries psychotherapy or trauma therapy is not available in a timely manner, this, in turn, leads to chronic diseases. Thus, people are psychologically damaged by increasing dependency, insecurity, fear, and the identification processes with the master as well as with his group. Stereotyping and the requirement of beautifying one's speech, as well as merging in the so-called 'guru yoga', serve to reduce access to one's own feelings and to deepen dependency. The seemingly required disintegration of boundaries, instead of development of self-reliance, endangers mental health. From a psychological perspective, along with the impact of physical and psychological violence and traumatization, the patterns of constant humiliation and the systematic questioning of one's own perception are detrimental, especially when this is tolerated for decades, believing it will serve the purpose of enlightenment. Some people consider themselves advanced, and assume that they are training in sophisticated meditation techniques, even though they actually just rehearse dissociation.

\subsubsection{Rationalisation of Damage for Silencing Trauma}

The following example reveals the pattern of systematic humiliation towards those of the 'inner circle': "With impatience, you have made demands for this entertainment and decadent sensory indulgences. When these are not made available at the snap of a finger, or exactly as you wished, we were insulted, humiliated, made to feel worthless, stupid and incompetent, and often hit or slapped" (Standlee et al. 2017, p. 6). Here, the shifting of anger to any other person willing to take it is illustrated: "or you were moody because you were upset with one of your girlfriends. There are hundreds of examples of trivial incidents that have set you off and your response has been to strike us violently" (Standlee et al. 2017, p. 4). In An Olive Branch report on the organization Shambala, out of 62 people contacting the listening post, there were "35 incidents of sexual misconduct [ ... 7 incidents of child abuse [ ... ] 10 incidents of physical violence" (An Olive Branch 2019b, p. 5). Sexual coercion was described in the open letter from the organization Rigpa, as follows:

You use your role as a teacher to gain access to young women, and to coerce, intimidate and manipulate them into giving you sexual favors. [ ... ] The ongoing controversies of your sexual abuse that we can read and watch on the Internet are only a small window into your decades of this behavior. Some of us have been subjected to sexual harassment in the form of being told to strip, to show you our genitals (both men and women), to give you oral sex, being groped, asked to give you photos of our genitals, to have sex in your bed with our partners, and to describe to you our sexual relations with our partners. You've ordered your students to photograph your attendants and girlfriends naked, and then forced other students to make photographic collages for you, which you have shown to others. You have 
offered one of your female attendants to another lama (who is well known in Rigpa) for sex. You have had for decades, and continue to have, sexual relationships with a number of your student attendants, some who are married. You have told us to lie on your behalf. (Standlee et al. 2017, p. 5)

This shows how, on the basis of the above-described concepts of merging, even with the wants of the perpetrator, the patterns of humiliation and manipulation, intimidation, coercion as well as seduction were mixed with sexual issues. Claiming that the subjects were bound to vows, which the group leader himself fails to keep, is evidence of their double standards. It is only a matter of time before people see through this and take their own steps: "You have always told us to be appreciative of the personal attention that you give, that you were 'pointing out our hidden faults' in our character, and freeing us from 'our self-cherishing ego'. We no longer believe this to be so" (Standlee et al. 2017, p. 4). The consequences of such behaviors are already showing, in a loss of trust. For instance, a person who attended seminars at Rigpa for approximately ten years shared the following: "I left immediately I heard about the abuse because I knew one person who highlighted it and knew they were honest and reliable" (Anders 2019c, respondent \#3). Thus, self-responsibility, developing self-awareness and trust in one's own perception, as well as supportive social relationships, rather than the social isolation and silencing resulting from the above-mentioned circumstances, are essential for regaining one's own strength and freedom. Furthermore, understanding that the pure view described for Vajrayāna practise is definitely not the pattern of positive thinking by all means, which serves as a panacea for all, might help one to think and care for oneself. That is, positive thinking is not an adequate means to solve the damage of trauma, depersonalization and silencing addressed here. Nor will victims benefit from hypocritical compassionate talk, instead they will find such talk to be cynical. Particularly, there is a need to restore their dignity and work to provide reparations, as addressed in the open letter:

We are not showing a lack of trust and respect, being a 'trouble-maker' with 'negative talk' as you often assert when anyone has dared to object to your methods. In fact, we have trusted you too long, given you the benefit of the doubt over and over again. When we've attempted to raise these concerns you've shamed us, and threatened to withhold the teachings from all the students because we had 'doubts'. (Standlee et al. 2017, p. 8)

When asked about personal experiences of indoctrination, one person replied:

Presenting a very narrow perspective of fundamentalist Tibetan Buddhism as the only true view. Selective and manipulative quotation from scriptures. Using Buddhist teachings to psychologically cleverly exploit needs [sic.] Avoiding systematic teaching on the basics of Buddhism, e.g., the actual teachings, e.g., ethics, and subtle dismissal of such teachings as low [sic.] Attempts to seduce people along rapid paths, e.g., Atiyoga, lacking one's own basics, lacking students' basics, or lacking basic knowledge on how to convey these. The sale of mere tradition-bound phenomena to be Buddhism. Establishing a Lamaism instead of Buddhism. Confusing 'Tibetism' with Vajrayana. (respondent \#1)

Such behaviors attempt to keep the 'students' in one's own organization and seduce them into lifelong schooling. The impact of self-exploitation, and payment for unending seminars on the lives of students is easily disregarded. The following statement was shared by someone from the organization Rigpa: "The teacher /lama said people were not to go outside the group for teachings. Other lamas /teachers were brought in to teach." (respondent \#3). Similarly, coercion was described by another person: "we were told not to take outside teachings and not to ever discuss teachings from outside the lineage, including the Buddha's words. My first teacher wanted to force me to give up my child and send her to a monastery. I refused and went over his head and said I was out if this was required. The teacher I appealed to agreed with me" (respondent \#6). Furthermore, the decontextualized use of the phrase 'crazy wisdom' and its usage to rationalize misbehavior and the subsequent damage is shown here: "You and others in your organization claim this is how a Buddhist master of 'crazy 
wisdom' behaves, just like the tantric adepts of the past. We do not believe this to be so and see such claims as attempts to explain away egregious behaviors" (Standlee et al. 2017, p. 5). Another example of elaborating on this neologism and its impact is found here:

Very often it was taught Lakar would apply wrathful wisdom, a traditional tool of TB, historically e.g., Milarepa. In this way the ground was prepared if disloyal students would report nonsense (i.e., the truth). The majority of them simply left without any attempts towards disclosure. Karma (negative) could be very quickly matured and passed in Lerab Ling in case of unpleasant events. Any small sign of whatsoever, even good weather, was considered 'magical'. A constant show was presented on how much Lakar would take care of all the students and he would work day and night for their good. Reality looked different. Most of the students he didn't know and he only cared about money and his reputation. Due to the high fluctuation of students, however, it would have taken a considerable effort on his part. Dharma was always taught in ways that fitted, e.g., what hells would await a person breaking samaya. However, no basics were taught whatsoever regarding sound knowledge of samaya and examining the [spiritual] teacher. In fact, hardly any Westerners ever have the chance to examine a Tibetan lama. This is impeded by language limitations, disassociation from the students and brief stays. In the case of Lakar, a highly professional image was created for those new and older students, who were not in the 'inner circle', that had nothing in common with reality. (respondent \#1)

Thus, it is important to deconstruct such pseudo-professional images, which deceive the public, and have a look at the education and integrity of a person, and their leadership qualities instead. The levels of manipulation and false praise for the promotion of some and the denigration of others were illustrated through the example of the organization Rigpa in Germany:

Typical public methods at Rigpa: public humiliation, abuse, exposure, exaggerated false praise, promoting or degrading people in the 'Rigpa Ranking'. Promoting and exploiting intrigues, power games and denunciation among students. Encouraging a sense of value within the collective and for the individual by cleverly presenting the Lama and his organisation as unique, exceptional, significant, superior to others, more advanced, etc. and then reducing the pupils to pocket size by public speech. I have called this attracting and domestising. Secrecy as a measure to create unofficial, subtle, non-formal structures within the so-called 'sangha'. Ideologically, this is justified by the selective use of specific parts of texts from the canon of Tibetan Buddhist texts, partly in a quite subtle and manipulative ways. Encouraging unhealthy ambitiousness and worldly interest by publicly displaying students' diligence, dedication, working enthusiasm, readiness to donate, etc. by setting up a gold standard in devotion. Great 'devotion' = greater progress on the path, thus also greater appreciation by the collective, thus higher ranking. The longing for alternatives for family and social belonging is being exploited to a very great extent. (Anders 2019c, respondent \#2)

These examples clearly illustrate the highly sophisticated psychological methods employed to internally promote some yet abuse others. Hence, it is not difficult to discern the kind of arrogance and intangibility established among the elites of the system, and the impact of such behavior and indoctrination on others who, for years or even decades, have invested their time and labor to gain access to spirituality and were played around with and abused. One person elaborated on the system of using people who were uneducated for their jobs and leaving out those who were well educated, which seems to be a strategy used in many of contemporary international Buddhist groups: "Very often utterly incompetent individuals were employed, I got the impression the permanent chaos associated with that allows for better manipulation" (Anders 2019c, respondent \#2). Someone who left the organization Pathgate after ten years shared the following information a few months after his separation: 
There is one single teacher in Pathgate [ ... ]. He functions as an authoritarian leader, dictating every aspect of students' lives [ ... ] gives Buddhist teachings, taichi and qigong [sic Taichi and Qigong] classes, provides advice to students, dictates their daily routines, and delegates jobs and functions for regular students, whether they are staying at the center or not. [ ... ] I realised that Pathgate was a cult and PY was behaving like a authoritarian cult leader. I concluded that his behaviour was unethical, narcissistic, manipulative and aggressive, which is not what an authentic Buddhist teacher should have. [ ... ] Psychologically, I feel anger, depression and a sense of injustice. Professionally, I have not been in a stable job for 6-7 years because PY has discouraged his students to detach from mainstream society. (respondent \#7)

He shared his testimony on violence and manipulation as follows:

I did not experienced violence towards me personally. I saw PY verbally abuse students on multiple occasions. I saw him humiliate students publicly several times. I saw him physically strike a female student on 1 [sic one] occasion. On these occasions the students were upset and crying after. I felt uncomfortable but I justified PY's abuse as 'crazy wisdom', that the teacher was using skilful methods to teach the students and 'purify their negative karma', Now I realise that there was no wisdom in PY's methods, he was simply abusive and there was no justification for it. Many students are so brainwashed and fearful of PY that they are conditioned to accept the abuse. (respondent \#7)

These examples show ways of rationalizing the damage employed in order to silence trauma and victims. That is used to divide people against each other and isolates the victims. Be it within the group or outside, this often constitutes secondary traumatization. Thus, the traditional doctrines distorted are the concepts of mindfulness and pure view - that is, the interpretations of what is translated as absolute and relative reality, and their respective methods of training, taking the goal as the path. Furthermore, there is a dangerous distortion in the teacher-student relationship, which impacts on the concept and method of guru yoga and the meaning of devotion in that context, as well as on the pure view's being ascribed to the teacher only. Moreover, the idea of 'karma purification' is a neologism that attracts people with cleansing fantasies, constitutes a risky mainstream uniting of purity, exclusiveness and exclusion and, in this way, presents challenges for society. If silencing the victim does not seem to be enough, other methods of isolation and intimidation are employed.

\subsubsection{Methods of Isolation and Intimidation-Portraying Others as Crazy or rlung Diseased}

In many societies, social isolation has been a tool employed for punishment. However, in some of these Buddhist groups, the isolation is employed for the traumatized victims of abuse, to demonstrate the strength of a leader against someone's autonomy, or because of the concealed jealousy of anyone in the entourage. People in power and their established entourage have the opportunity to use social isolation by spreading rumors about someone, employing public slander or ordering others to do so. And such slander campaigns are not limited to group borders, but may be extended to members' social background, key relationships or professional relationships. Nowadays, due to the internationality of these groups, they can go far beyond national borders. While victims previously had the opportunity to move home or relocate abroad, such strategies no longer work. Inside the group, any offense can be justified using the new concept of 'karma purification'. By then publicly framing such methods, as well as the individuals' isolation, as the victim's perception problem, the perpetrators have little to fear from within. Moreover, those who begin to doubt the legitimacy of such methods may be sufficiently scared of being made victims themselves. Thus, the extent to which the unreflective adoption of these concepts, by people who consider themselves not bound by any national law due to their religious elevation leads to can be seen. Unfortunately, projecting one's ideals onto a Tibetan myth and the overall indiscriminate idealization of Buddhist values has prevented corresponding societal measures being taken to investigate and respond to the conditions behind the superficial image, and to limit 
its dangers to society. Particularly within psychotherapeutic contexts, the mainstream idealization of mindfulness meditation has hindered victims from being heard, taken seriously and receiving the required psychotherapeutic treatment. It is these confusing and grueling methods, covertly applied in a group, that, over many years, have made people sick. Another method to avoid self-responsibility and being held accountable is to distract from violence, exploitation and abuse by stating that there was no intention to harm, as if the damage to the victim were less severe because of the rationalized intention of the perpetrator. Furthermore, in instances where a person is among those who can define and change the rules, it is always possible to harass someone by simply publicly accusing the person of having broken rules -those in power may even alter the rules the second before the complaint, if needed-for reasons such as jealousy. In such cases, although there was no fault to criticize, there usually are no consequences for the perpetrator. Such conditions result from imported hierarchies, based on the assignment of positions to unqualified or ethically incapable persons, and the failure to implement democratic processes, which results in members being unable to remove a person, and the absence of legal implementation, as though these structures were beyond public legal frameworks, as well as the terminological tricks used. Another method commonly employed in traditional Tibetan contexts is refusing communication altogether, which is rationalized as the "breakthrough of truth":

In both his letter to me of 4 July 2018, and the letter 18 July 2017 to the eight letter writers, I noted that Sogyal did not deny the allegations against him, but instead pointed out that he did not ever intend to cause harm. Having heard evidence from a number of witnesses and listened to some recorded teachings by Sogyal, I have concluded that it would not be safe to treat his lack of denial as a tacit admission. Sogyal has stated publically that he considers that he will not defend himself against attack, and others (e.g., Witness N) spoke to me of the Buddhist belief that there is no need to respond to any form of attack against you -'wait and the truth will come'. (Baxter 2018, p. 10)

However, sitting out of issues of such magnitude will not lead to any constructive solutions, but rather cause damage and disputes over decades-the resolution of which is merely postponed to future generations. Considering the retrospective whitewashing of historiography to preserve the elite's influence, common hypocrisy (Sogyal 2019; Carreon 2019) and so-called masters who assume themselves beyond legislation, a good first step for our societies would be to invoke human rights concerns and their implementation, along with claiming compensation payments from the organizations that have enriched themselves at the expense of their victims. Such a system of slandering, systematically humiliating women and stigmatizing people, even with terms referring to psychiatric diseases, creates distress and fear in the group and for the individual. This is because people know that, if they become the center of attention for whatever reason, or if they dare to withdraw from the group or even leave it, they will be treated the same way. Stalking is also a common method, including but not only at the organization Rigpa. From the organization Rigpa:

It was striking that Rigpa wanted to find out if and which other teacher I would turn to. [ ... ] When I first came to a seminar, rather soon after I had left, I met a 'senior student' of Rigpa, we knew each other. He was a bit uneasy about me. He had already conveyed messages from Sogyal Lakar to other Lamas on several previous occasions, as I knew. Anyway, as Rigpas' representative, he paid his respects and handed over a letter. Then the Lama intensely looked at me, and upon parting he told me to come again, in a compassionate tone. I cannot prove it, but I know of similar cases where lamas were informed that student xyz would come, he/she would have difficulties, or too much lung or something similar. At this point I would consider that as a precaution against negative information about Sogyal Lakar which ex-disciples could tell. (Anders 2019c, respondent \#2)

These experiences result in distrust, not only in others but also in oneself, which was described as follows: 
Distrust. Trusting other people has become much more difficult for me than it was when I was younger, before my participation in an abusive sangha. Boundary: By this I intend to clearly disassociate from people who act strongly dishonest, who permanently manipulate, and/or who present characteristics of belonging to particular subcultures. Anger: When it comes to abuse in religious groups and concealment, and when ritualised behaviour is being sold for spiritual practice, my fuse has become quite short. Resignation: I have no more patience to use energy and time on others. (respondent \#1)

The challenging group structures described above were developed based on inherited hierarchical command structures, decontextualized concepts and neologisms, as well as on psychological manipulations that were unquestioned for decades. However, since they not only impact the individuals and their health, but, due to the situation of many individuals, also on society, its judgement and attention to this are now required. The following chapter illustrates some consequences for the victims.

\subsubsection{Breakdown of People}

Due to economic abuse, which many people do not see any way out of, considering their loss of resources due to conceptual preconditions of 'karma purification', together with the dangers of stalking and slander when simply distancing themselves from or leaving such a group (Anders 2019b, 2019c), there are prolonged stays in, and delayed separation processes from, these organizations. People often abandon external social contacts in favor of their group, which is reinforced by doctrines forbidding engagement with non-Buddhists and joining other Buddhist groups (Anders 2019b, 2019c). However, even within their group, members receive little support in the case of damage, due to the conceptualization of 'karma purification', implemented or ordered by a supreme authority, which has to be accepted by all group members and will otherwise negatively affect them, the assignation of psychiatric diseases to those one wants to get rid of and the common taboo surrounding abuse. The loss of social contacts in turn impacts negatively on mental health. However, the unconscious dynamics of fear that such could also impact oneself in the same ways should also be taken into consideration. This means that, over the years, a system of fear builds up behind the surface of a seemingly harmonious community. This becomes even more complicated when a cult, such as Ogyen Kunzang Choling (OKC) in Europe, invites respected and venerated Tibetan Buddhist authorities to teach seminars and they accept the invitation, which is another kind of whitewashing routine (\#OKCinfo ex-OKC born-kids, slide 19). Considering the indoctrination, harassment, double bind and physical injuries, inflicted on members and seminar participants, mental diseases are the obvious outcome. Due to the delayed departure from the group and members' lack of social and economic resources after unscrupulous exploitation by such groups, these diseases are often complex and chronic. Thus, child abuse, and the seduction and coercive control of adults under a spiritual umbrella (An Olive Branch 2019b, pp. 26-27; \#OKCinfo ex-OKC born-kids; \#OKCinfo ex-OKC born-kids, slide 7, slide 37) as well as a lack of education (\#OKCinfo ex-OKC born-kids, slide 28) forms the structural and contextual background which should be considered when analyzing evidence regarding damage to individuals. Often, the victims of abuse themselves emphasize that the psychological impact exceeds the physical injury:

Your emotional and psychological abuse has been perhaps more damaging than the physical scars you have left on us. When we have worked for you while organizing and setting up the infrastructure for you to teach at different places around the world (Europe, North America, Australia, and India and Nepal), your shaming and threatening have led some of your closest students and attendants to emotional breakdowns. (Standlee et al. 2017, p. 4)

Asked for the testimony or personal experience of people's breakdown, one testimony stated:

People asking critical or unwanted questions were talked down, humiliated, marginalised, ridiculed, or got a special corruptive treatment, original tone: 'You're that far, we may introduce Rinpoche directly, if you like'. People who broke mentally for various reasons 
were made a case for Sanghacare. This usually meant that one was desperately looking for someone to whom the person was referred, who was not from the Sanghacare. It was quickly moving from hand to hand just like a hot potato. As these 'cases' also ended up with me, I have personally experienced this several times. Once the issue was solved, or alleviated, Sanghacare would praise herself on her great work. By the way, it was striking how many students of Lakar accepted tasks, quickly looking for someone else to 'do the

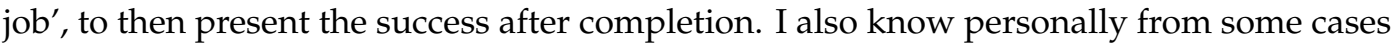
that they were being 'psychologically' approached: Admonition, angry impression, threats (samaya and other consequences), withdrawal of love, exposing (this also has an intensive effect on others). Intimidation, bad cop-good cop-playing, acting authoritatively, focused attention and attentive love-bombing. (respondent \#1)

In addition to the development of mental diseases and the frequently fragile economic situation of those concerned when leaving such an organization, however, they lost confidence in elitist masters and suffer a spiritual crisis.

\subsubsection{Spiritual Crisis and the Concept of One's Own Spirituality Depending on a Male Master}

Although a spiritual crisis may have already developed while participating in the group, it often only comes to consciousness when the acute economic and psychological crisis subsides. For ordained people, who are required to take off their robes in order to make their living, this may involve even more complex processes of disidentification and dealing with emotions such as shame or guilt. Someone shared the following: "I wasted almost 2 decades of my life as a monk. I missed out on many normal life experiences because I was stupid and idealistic. I regret everything. I miss my other friends" (Anders 2019c, respondent \#4). Another respondent stated that, "being a Buddhist and monk was a huge part of my identity, social interaction, and worldview and leaving put me into an existential and psychological crisis. I'm doing better now, but it was scary. My therapist was not really familiar with spiritual crises" (respondent \#4). Others talk about the effects of the information they received: "I no longer identify as any type of Buddhist as a result of the harm that has befallen people I love at the hands of abusive clergy and a corrupt and complicit hierarchy and laity, but I was ordained as a monk in the Drikung Kagyu tradition of Tibetan Buddhism for 18 years [ ... ] and have practiced and studied Nyingma and other lineages as well as Chinese and Japanese Buddhism" (Anders 2019c, respondent \#4). For whatever reason, many people regard their spirituality as only being accessible through a mediator or through identification with a leader figure. Thus, such a high level of identification with the master and his organization, and the resulting delegation of self-responsibility to him, seems to be quite seductive. By identifying with their master and group, people deceive themselves, instead of learning to undertake an inner, self-reflexive process by using the methods described in the original languages within Buddhist texts. Some even consider their emotional excitement and the fantasies regarding the colorful imagery of Tibetan Buddhism to be insight or realization. Although initially the personal gains and the economic resources acquired may seem to prove this attitude right, it is a dead end in terms of Buddhist practise. Some were even misguided in terms of the thought of bodhicitta, just as in this case: "I no longer attend any Buddhist centers or seminars, but attended many in the past [sic.] I used to attend because I believed in cultivating qualities associated with the bodhisattva ideal and wanted to help decrease the suffering of sentient beings" (respondent \#4). It is important to understand that spirituality goes far beyond such a narrow frame of helping. In traditional Vajrayāna, it is about clarity and the unfolding of capacity, based on realizing the light of clarity.

\subsection{Impact}

The commercialization of Buddhist concepts and terminology has led to considerable terminological confusion, which has even reached the field of science. Mindfulness being promoted as a panacea, while disregarding context or culture, is only one example of this (Attersee Anders 2016, p. 46). 
The damage to the knowledge imparted in Buddhist philosophy by the distortion of concepts, commercializing spiritual methods for (psycho)therapy, and indoctrinating as well as abusing people, cannot be estimated yet. It may take a few generations to clear the terminological chaos, go beyond the silencing of victims and heal the wounds of psychological trauma. This is especially true in terms of its impact, treatment and transgenerational transmission. The pattern of unquestionably idealizing anyone who claims him- or herself a dignitary of Buddhist meditation or Vajrayāna, without at least inquiring about his education, reviewing his integrity and leadership qualities, as well as evaluating his individual level of maturity, has paved the way towards an increasing loss of social control. As the financial inflow and the inflated notion of their own grandiosity seemed to prove such organizations right for a long time, the question of where this lack of self-responsibility (Anders 2019d) and social control would lead in the long run hardly arose. However, the unequal distribution of power arrangements, which incited conflicts in and among groups, as well as damaging their students' compassion for other students and stigmatizing and silencing victims, will change, depending on the individuals' ability to assume self-responsibility, rethink their social structures and find their own spirituality without mediators. As soon as those affected succeed in truly acting jointly and in solidarity, inevitable changes will be initiated. Society is now challenged with providing for the compensation and treatment of victims, claiming refunds from these international Buddhist organizations and providing their members and seminar participants with methods for spiritual autonomy. This current pile of fragments arose from a failure to assume leadership responsibility and accountability, along with a lack of acknowledgement of the personal and social impact of the unconscious. As the shadow of the unconscious tends to be projected towards the female, even when attempting to reconcile this by visualizing female Buddhas in a way that is incompatible and ambiguous, one might consider measuring change against genuine dialogue with women.

\section{Self-Responsibility, Autonomy and Integrity as Factors for Change and Knowledge Preservation}

An unreflective decontextualizing of concepts and interventions in the name of Buddhist religion has turned them into dangerous balancing points, threatening people's mental and physical health. Besides the methods of silencing, the enforced isolation of victims needs to be addressed in order for change to come about. If we fail to face the challenge of healing these wounds and restructuring existing infrastructure to avoid further damage in the name of Vajrayāna, not only will its knowledge be lost, but the stories of all the victims will remain silenced, and serious hostilities will emerge, that are no longer easy to cure. Since, in this period of time, the Vajrayāna has lost its heart, which is the very bodhicitta, any practice merely carrying its name will not lead to the intended consequences, either. Therefore, what is needed now is the devotion for the path itself. Although much more analysis is needed to understand the impact of the conscious and unconscious dynamics at work and the silencing of trauma, the necessary change will come about by counteracting the maintenance of power imbalances, and making self-responsible decisions. If these acts of resistance allow for autonomy, responsible acts of compassion and integrity, they will impact positively on the preservation of the meaning of Vajrayāna.

Funding: This research was funded by the Federal Ministry of Education and Research, grant number 01UL1823X.

Conflicts of Interest: The author declares no conflict of interest. The funders had no role in the design of the study; in the collection, analyses, or interpretation of data; in the writing of the manuscript, or in the decision to publish the results.

\section{References}

\#OKCinfo (ex-OKC born-kids). 2019a. Sexual Abuses of Young Girls. Available online: https://www.okcinfo.news (accessed on 6 September 2019).

\#OKCinfo (ex-OKC born-kids). 2019b. 40 Years of Abuse in the Name of Dharma the Story of Ogyen Kunzang Choking and Lama Kunzang Dorje, (aka Robert Spatz, or RS in This Presentation). Available online: https://okcinfo.news/archives/ (accessed on 6 September 2019). 
An Olive Branch. 2019a. Shambhala Final Project Report. Available online: https://www.dropbox.com/s/ eloezy0vc0nhgro/AOB_FinalReport_March2019_final.pdf?dl=0 (accessed on 20 March 2019).

An Olive Branch. 2019b. Report on the Shambhala Listening Post. Available online: https://www.dropbox.com/s/ 111arue9y4gtk73/AOB_ListeningPostReport_March2019_final.pdf?dl=0 (accessed on 20 March 2019).

Anders, Anne I. M. 2019a. Psychische Auswirkungen von Machtmissbrauch in buddhistischen Gruppierungen und essenzielle Aspekte bei psychotherapeutischen Interventionen für Betroffene. SFU Forschungsbulletin 7: 32-49. Available online: http://journals.sfu.ac.at/index.php/sfufb/article/view/245/276 (accessed on 30 June 2019). [CrossRef]

Anders, Anne I. M. 2019b. Forschungsergebnisse-Zitate von Zeitzeugen aus Deutschland Aktuelle Zeitzeugenaussagen aus unterschiedlichen Organisationen. Available online: https://www.transtibmed. ethnologie.uni-muenchen.de/zeitzeugenberichte/deutsch/deutsche_zitate_forschung/index.html (accessed on 1 July 2019).

Anders, Anne I. M. 2019c. Research Results the Following Results are from the Research Project TransTibMed and Provide Contemporary Witness Reports. Available online: https://www.en.transtibmed.ethnologie.unimuenchen.de/testimonies/research-results/index.html (accessed on 1 July 2019).

Anders, Anne I. M. 2019d. Addressing Current Incidents in Buddhist Communities and Self-Responsibility. Available online: https://www.en.transtibmed.ethnologie.uni-muenchen.de/publications/current-issuesresponsibility/index.html (accessed on 29 May 2019).

Attersee, Anne I. M. 2014. Kognition und Emotion in der Tibetischen Medizin Eine Darstellung und Interpretation aus Emischer Perspektive. Aachen: Shaker.

Attersee Anders, Anne I. M. 2016. Selbstreferenz Ein dynamisches Selbstreferenzmodell auf der Grundlage von graduellem kognitivem Training. Wiesbaden: Springer.

Attersee Anders, Anne I. M. 2017. Introspektion als Wirkfaktor in der Psychotherapie Eine psychotherapiewissenschaftliche Modellbildung zu Effektstrukturen des Graduellen Kognitiven Trainings. Wiesbaden: Springer.

Baker, Connie A. 2019. Traumatised by Religious Abuse. Discover the Cultures and Systems of Religious Abuse and Reclaim Your Personal Power. Eugene: Luminare Press.

Baxter, Karen. 2018. Report to the Boards of Trustees of: Rigpa Fellowship UK, and Rigpa Fellowship US. Outcome of an Investigation into Allegations Made Against Sogyal Lakar (also known as Sogyal Rinpoche) in a Letter Dated 14 July 2017. Available online: https://static1.squarespace.com/static/580dbe87e6f2e16700cb79fe/t/ 5b8f7c1e1ae6cfb38491e668/1536130081917/Lewis+Silkin+report.pdf (accessed on 1 September 2018).

Berzin, Alexander. 2010. Wise Teacher, Wise Student. Tibetan Approaches to a Healthy Relationship. Ithaca and New York: Snow Lion.

Carreon, Charles. 2019. Dharma Teachers: Please Retract Your Homages to Sogyal. Available

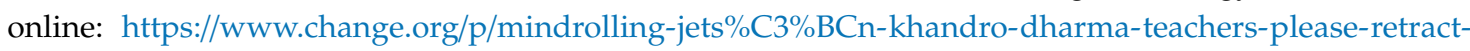
your-homages-to-sogyal (accessed on 4 September 2019).

Coleman, Graham, and Thupten Jinpa, eds. 2008. Das Tibetische Totenbuch. Die Große Befreiung durch Hören in den Zwischenzuständen. München: Arkana.

Dalai, Lama. 1992. Einführung in den Buddhismus. Freiburg: Herder.

Dudjom, Jikdrel Y. D. 1991. The Nyingma School of Tibetan Buddhism. Its Fundamentals and History. Boston: Wisdom Publications.

Finnigan, Mary. 2019. 4) Trungpa Rinpoche and the Rock Star Lifestyle November 20, 2011. Available online: https://behindthethangkas.wordpress.com/2011/11/20/4-trungpa-rinpoche-and-the-rock-star-lifestyle/ (accessed on 14 January 2019).

Finnigan, Mary, and Rob Hogendoorn. 2019. Sex and Violence in Tibetan Buddhism the Rise and Fall of Sogyal Rinpoche. Portland: Jorvik Press.

Gyalchok, Shönu, and Könchok Gyaltsen. 2006. Mind Training. The Great Collection. Boston: Wisdom Publications. Hark, Helmut. 1988. Lexikon Jungscher Grundbegriffe. Olten: Walter Verlag.

Hassan, Steven. 2013. Freedom of Mind. Helping Loved Ones Leave Controlling People, Cults and Beliefs. Newton: Freedom of Mind Press.

Hassan, Steven. 2018. Combating Cult Mind Control. The\#1 Best-Selling Guide to Protection, Rescue, and Recovery from Destructive Cults. Newton: Freedom of Mind Press.

Herman, Judith L. 2015. Trauma and Recovery. The Aftermath of Violence—From Domestic Abuse to Political Terror. New York: Basic Books, Member of Perseus Books Group. 
Jung, Carl G. 1990. Die Beziehungen zwischen dem Ich und dem Unbewussten. Olten: Walter Verlag.

Kongtrul, Jamgön L. T. 1999. The Teacher-Student Relationship. Boston: Snow Lion.

Kongtrul, Jamgön L. T. 2003. The Treasury of Knowledge Book Five: Buddhist Ethics. Boston and London: Snow Lion. Kongtrul, Jamgön L. T. 2012. The Treasury of Knowledge Book Seven and Book Eight, Parts One and Two Foundations of Buddhist Study and Practise. Boston and London: Snow Lion.

Köttl, Miriam. 2009. Heilung aus der Perspektive Tibetischer Medizin. Aachen: Shaker.

Langel, Helmut. 1995. Destruktive Kulte und Sekten. Eine kritische Einführung. München and Landsberg: Moderne Industrie.

Morman, Craig, Ben Medrano, Laura Leslie, Louis Fitch, David Ellerton, and Allya Canepa. 2019. An Open Letter to the Shambhala Community from Long-Serving Kusung. Available online: $\quad$ https://drive.google.com/file/d/1W3fN12nEY-10U2yejz3O4vcqaCMfusIa/view? fbclid= IwAR0Qo3zbWkJ3E5wjPUhLoVwOJnKwZee_AAzA79kvgj9K6DcOfh5uU7p5pM0 (accessed on 16 February 2019).

Newland, Thalia. 2019. Fallout. Recovering from Abuse in Tibetan Buddhism. Australia: Escarpment Publishing.

Patrul, Rinpoche. 1998. Words of My Perfect Teacher. A Complete Translation of a Classic Introduction to Tibetan Buddhism. New Delhi: Vistaar Publications.

Richard, Matthieu, and Kurz Vivian, eds. 2010. The Collected Works of Dilgo Khyentse. Volume Two the Excellent Path to Enlightenment. The Wheel of Investigation. The Wish-Fulfilling Jewel. The Heart Treasure of the Enlightened Ones. The Hundred Verses of Advice. Boulder: Shambala Publications.

Sogyal, Rinpoche. 2019. Paying Homage to Sogyal Rinpoche. First published 2018. Available online: https://sogyalrinpoche.org/paying-homage-to-sogyal-rinpoche (accessed on 4 September 2019).

Standlee, Mark, Damcho Sangye, Matteo Pistono, Joanne Standlee, Graham Price, Michael Condon, and Gary Goldman. 2017. Open Letter to Sogyal Lakar. Available online: https://www.lionsroar.com/wp-content/ uploads/2017/07/Letter-to-Sogyal-Lakar-14-06-2017-.pdf (accessed on 1 August 2017).

Tsepak, Rigzin. 2003. Tibetan-English Dictionary of Buddhist Terminology. Dharamsala: Library of Tibetan Works and Archives.

Winn, Andrea M. 2018. Project Sunshine: Final Report. A Firebird Year Initiative to Bring Light and Healing to Sexualized Violence Embedded Within the Shambhala Community February 27, 2017-February 15, 2018. Available online: www.andreamwinn.com/pdfs/Project_Sunshine_Final_Report.pdf (accessed on 1 January 2019).

Winn, Andrea M., and Carol Merchasin. 2018a. Buddhist Project Sunshine Phase 3. Final Report. The Nail: Bringing Things to a Clear Point A 2-Month Initiative to Bring Activating Healing Light to Sexualized Violence at the Core of the Shambhala Buddhist Community August 23. Available online: andreamwinn. com/project_sunshine/Buddhist_Project_Sunshine_Phase_3_Final_Report.pdf (accessed on 1 January 2019).

Winn, Andrea M., Richard Edelman, Carol Merchasin, Elizabeth Monson, and Women Survivors. 2018b. Buddhist Project Sunshine Phase 2. Final Report. A 3-Month Initiative to Bring Healing Light to Sexualized Violence at the Core of the Shambhala Buddhist Community June 28. Available online: andreamwinn.com/project_ sunshine/Buddhist_Project_Sunshine_Phase_2_Final_Report.pdf (accessed on 1 January 2019).

Zopa, Lama R. 2019. Lama Zopa Rinpoche's Advice to Students of Dagri Rinpoche. Available online: https:/fpmt.org/lama-zopa-rinpoche-news-and-advice/advice-from-lama-zopa-rinpoche/lamazopa-rinpoches-advice-to-students-of-dagri-rinpoche/ (accessed on 14 May 2019).

(C) 2019 by the author. Licensee MDPI, Basel, Switzerland. This article is an open access article distributed under the terms and conditions of the Creative Commons Attribution (CC BY) license (http://creativecommons.org/licenses/by/4.0/). 